Supporting information for

\title{
Simultaneous orthogonal methods for the real-time analysis of catalytic reactions
}

\author{
Robin Theron, ${ }^{\mathrm{a}}$ Yang Wu, ${ }^{\mathrm{a}}$ Lars P. E. Yunker, ${ }^{\mathrm{a}}$ Amelia V. Hesketh, ${ }^{\mathrm{a}}$ Indrek Pernik, ${ }^{\mathrm{b}}$ Andrew S. \\ Weller ${ }^{\mathrm{b}}$ and J. Scott McIndoe ${ }^{\mathrm{a}}$
}

a. Department of Chemistry, University of Victoria, P.O. Box 3065 Victoria, BC V8W3V6, Canada. Fax: +1 (250) 721-7147; Tel: +1 (250) 721-7181;E-mail: mcindoe@uvic.ca

b. Department of Chemistry, University of Oxford, Mansfield Road, Oxford, OX1 3TA, UK.

\section{Table of Contents}

Figure S1. a) Bruker Alpha FT-IR with a Harrick transmission flow cell. b) KNF Lab Simdos 02

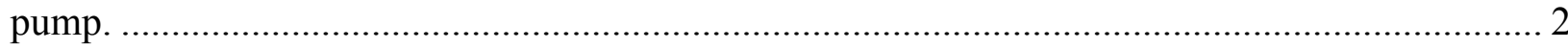

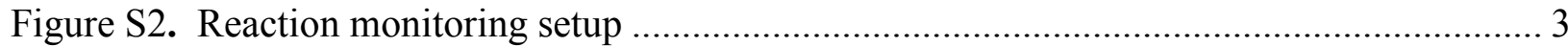
Figure S3. IR absorbance spectrum of 2-(methylthio)benzaldehyde (1) and 1-octyne mixture in 1,2-dichloroethane (DCE)...

Figure S4. IR absorbance spectrum of 1-(2-(methylthio)phenyl)non-2-en-1-one (3) and 1-octyne

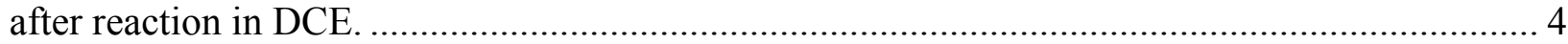

Figure S5. Calibration curve for 2-(methylthio)benzaldehyde (3) . .................................... 5

Figure S6. Plot of natural $\log$ of the signal intensity due to aldehyde against time..................... 5

Figure S7. Catalyst concentration effect on rate constant for reaction 1-5\% catalyst loadings...... 6

Figure S8. Alkyne loading effect on rate constant for reaction 1-10x alkyne equivalents............ 6

Figure S9.Temperature effect on rate constant for reaction, 273 to $315 \mathrm{~K}$. ............................ 7

Table S1. Summary of reaction conditions and rates. ..................................................... 7

Figure S10. PSI ESI-MS reaction profile of the most abundant species seen by MS................. 8

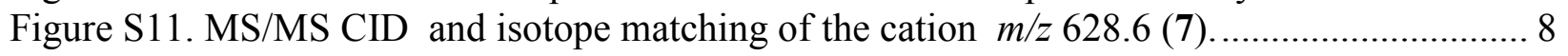

Figure S12. ESI-MS Ion count intensities of precatalyst 4 and product-bound catalyst 7.......... 9

Figure S13. PSI ESI-MS reaction profile, showing species with abundances $\sim 1 / 8000^{\text {th }}$ that of the

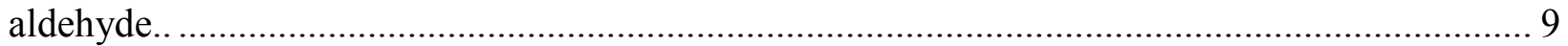

Figure S14. MS/MS CID and isotope matching of the cation $m / z$ 490.5. (8 and 9) ................ 10

Figure S15. MS/MS CID and isotope matching of the cation $m / z 444.4(\mathbf{1 0}) \ldots \ldots \ldots \ldots \ldots \ldots \ldots \ldots . . . \ldots \ldots$

Figure S16. MS/MS CID MS/MS CID and isotope matching of the cation $\mathrm{m} / z 474.5$ (11) ...... 11

Figure S17. PSI-ESI Reaction profile showing the effect of cyclooctadiene on catalyst speciation. 
Figure S18. MS/MS CID and isotope matching of the cation $m / z 433.2$ (12)

Figure S19. (a) ESI-MS of 4 before addition of pyrrole; (b) 12 minutes after addition of pyrrole to a solution of 4. in DCE. $\left[\mathrm{Rh}\left(\mathrm{L}_{2}\right) \text { (pyrrole) }\right]^{+}$forms and has an MS/MS product spectrum identical to that of species 12 . 13

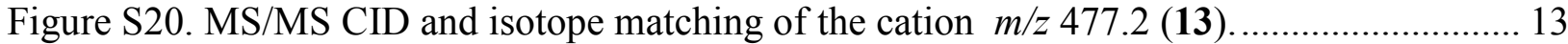

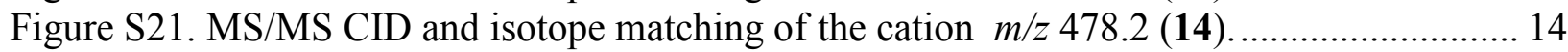

Figure S22. Reproducibility of the PSI ESI-MS reaction profile for 8-14 ............................ 15

Figure S23. Reproducibility of the PSI ESI-MS reaction profile for 5 ................................ 16

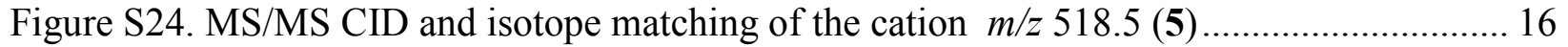
Figure S25. PSI ESI-MS reaction profile, decomposition product, ultra-low abundance species..

Figure S26. MS/MS CID and isotope matching of the cation $\mathrm{m} / \mathrm{z} 698.3(\mathbf{1 5})$ 17

Figure S27. MS/MS CID and isotope matching of the cation $\mathrm{m} / z 738.8$ (16) 17

Figure S28. MS/MS CID and isotope matching of the cation $m / z 770.4$ (17) 18

Figure S29. Reproducibility of the PSI ESI-MS reaction profiles of 15, 16, and 17. 18 19
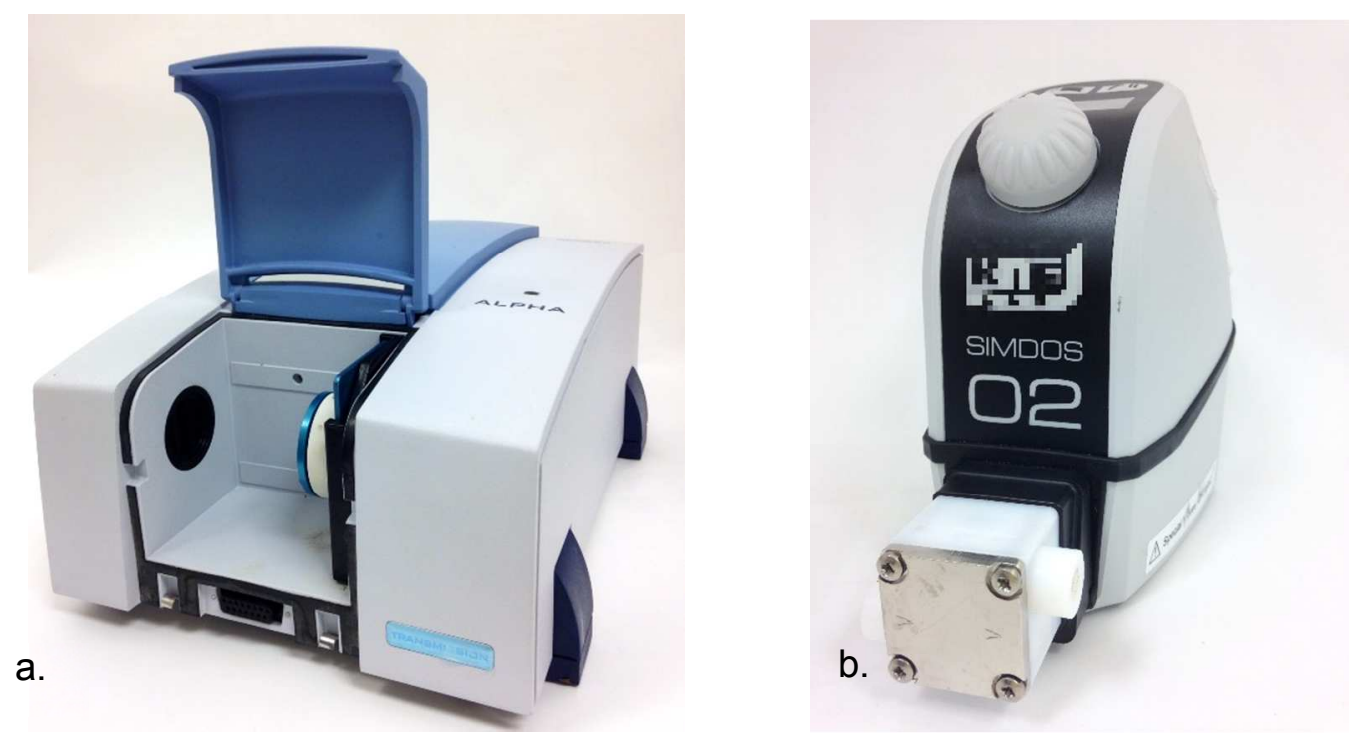

Figure S1. a) Bruker Alpha FT-IR with a Harrick transmission flow cell. b) KNF Lab Simdos 02 pump. 


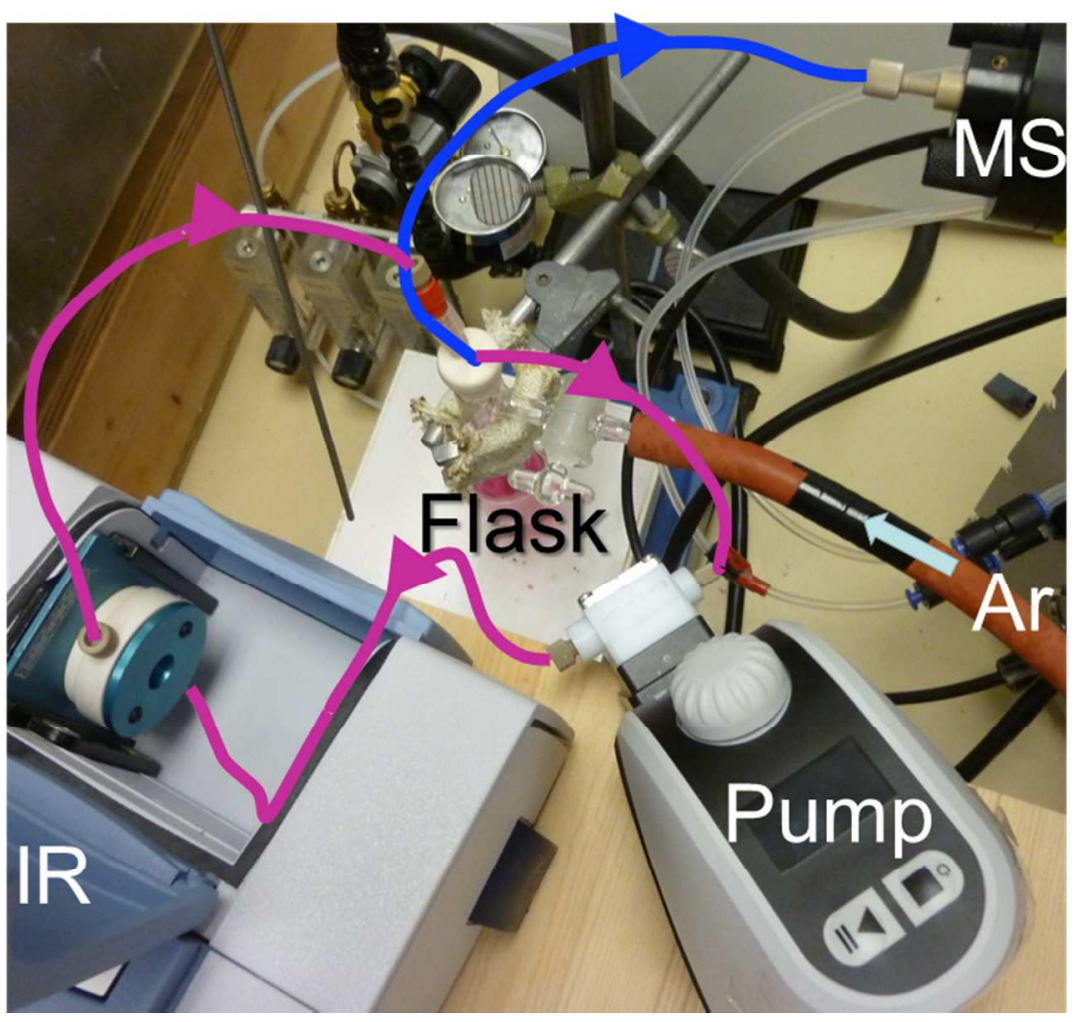

Figure S2. Reaction monitoring setup with reaction solution continually fed to ESI-MS by an overpressure applied by an argon cylinder (blue arrow), and circulation of the reaction solution through the flow cell of the FT-IR by the pump (magenta arrows). The rate of circulation through the loop to the transmission cell and back into the flask was determined to be optimal at $2.5 \mathrm{ml} / \mathrm{minute}$, allowing for a minimal time lag between reaction progress and sampling time instances. The tubing used had an inner diameter of 200 $\mu \mathrm{m}$, narrow enough to allow for small volumes being taken up in the tubing while wide enough not to create appreciable back pressure in the circulation pump. A $100 \mu \mathrm{m}$ path-length was used in the transmission cell because this allowed for a strong signal, while also letting the flow cell have a minimal volume. The total volume loop made up of the flow-cell, tubing, and pump-head was determined to be $700 \mu \mathrm{L}$. Thus at a circulation rate of $2.5 \mathrm{ml} /$ minute, the loop would be cleared every 17 seconds, so a scanning rate of a set of IR scans every 20 seconds was settled on. 


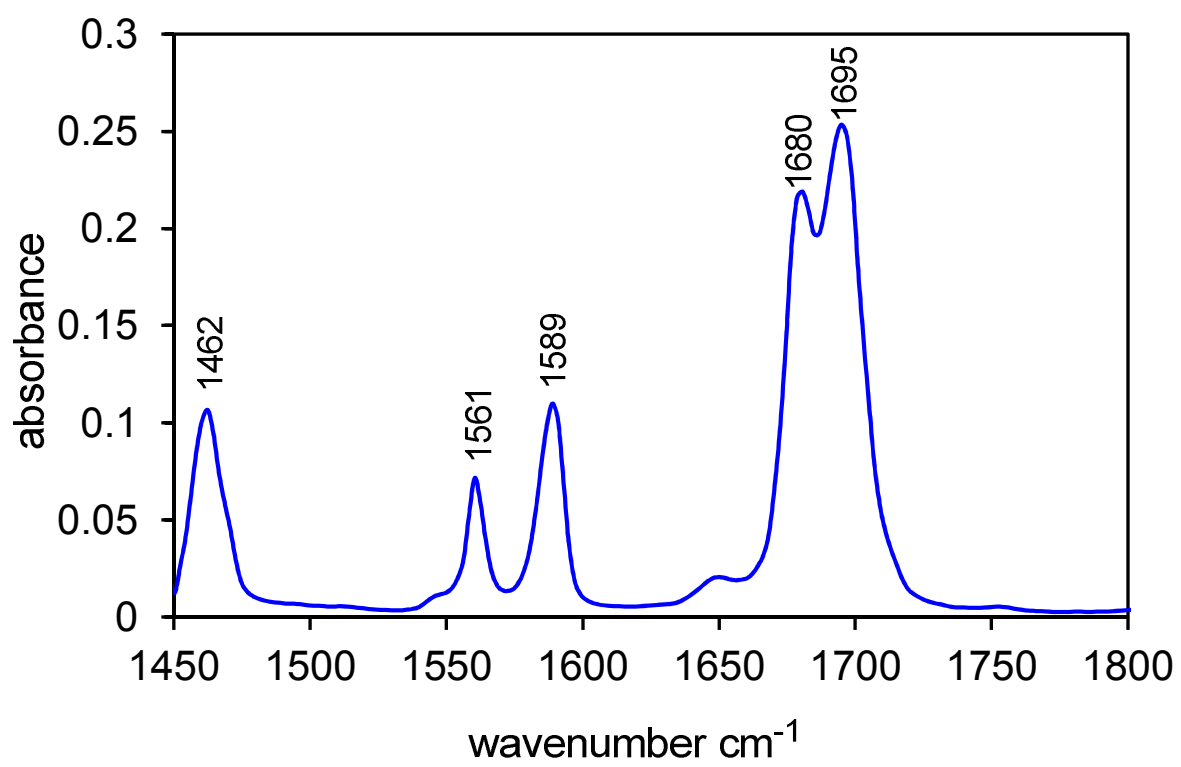

Figure S3. IR absorbance spectrum of 2-(methylthio)benzaldehyde (1) and 1-octyne mixture in 1,2dichloroethane (DCE). $16 \mathrm{~s}$ data collection, $1 \mathrm{~s}$ scans repeated 16 times and summed. The aldehyde showed strong carbonyl stretches at $1695 \mathrm{~cm}^{-1}$ and $1680 \mathrm{~cm}^{-1}$ and absorptions at 1589 and $1560 \mathrm{~cm}^{-1}$ due to aromatic stretching modes. The reaction is effective in non-coordinating chlorinated solvents, (DCE) has a high enough boiling point to allow reactions at elevated temperature, and its IR absorption properties leave a relatively open window between $2900-1500 \mathrm{~cm}^{-1}$.

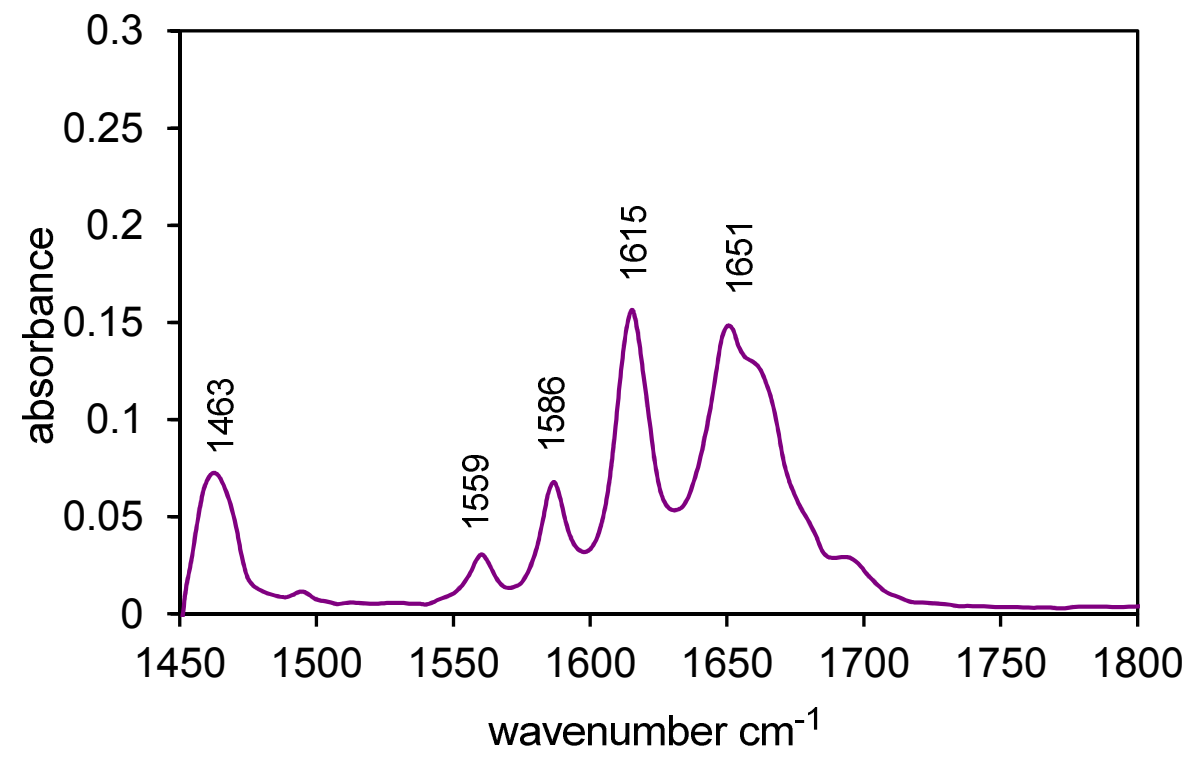

Figure S4. IR absorbance spectrum of 1-(2-(methylthio)phenyl)non-2-en-1-one (3) and 1-octyne after reaction in DCE. $16 \mathrm{~s}$ data collection, $1 \mathrm{~s}$ scans repeated 16 times and summed. The $\alpha, \beta$-unsaturated ketone has a carbonyl stretch at $1650 \mathrm{~cm}^{-1}$, which is lower than an aliphatic ketone carbonyl due to the conjugation in the molecule. The alkene part of that molecule has a $C=C$ stretch at $1615 \mathrm{~cm}^{-1}$ which is a strong absorption, consistent with literature as the absorption frequency of an alkene conjugated with a carbonyl group is generally found at lower frequencies and the intensity of the absorption can be strong; the $\mathrm{C}=\mathrm{C}$ stretches can be as strong as a carbonyl stretch. ${ }^{1}$ See http://webbook.nist.gov/cgi/cbook.cgi?|D=C78944\&Units=SI\&Type=IR-SPEC\&Index=1\#IR-SPEC for an example of the IR spectrum of a conjugated phenyl ketone (also 3 peaks in the CO stretching region) 


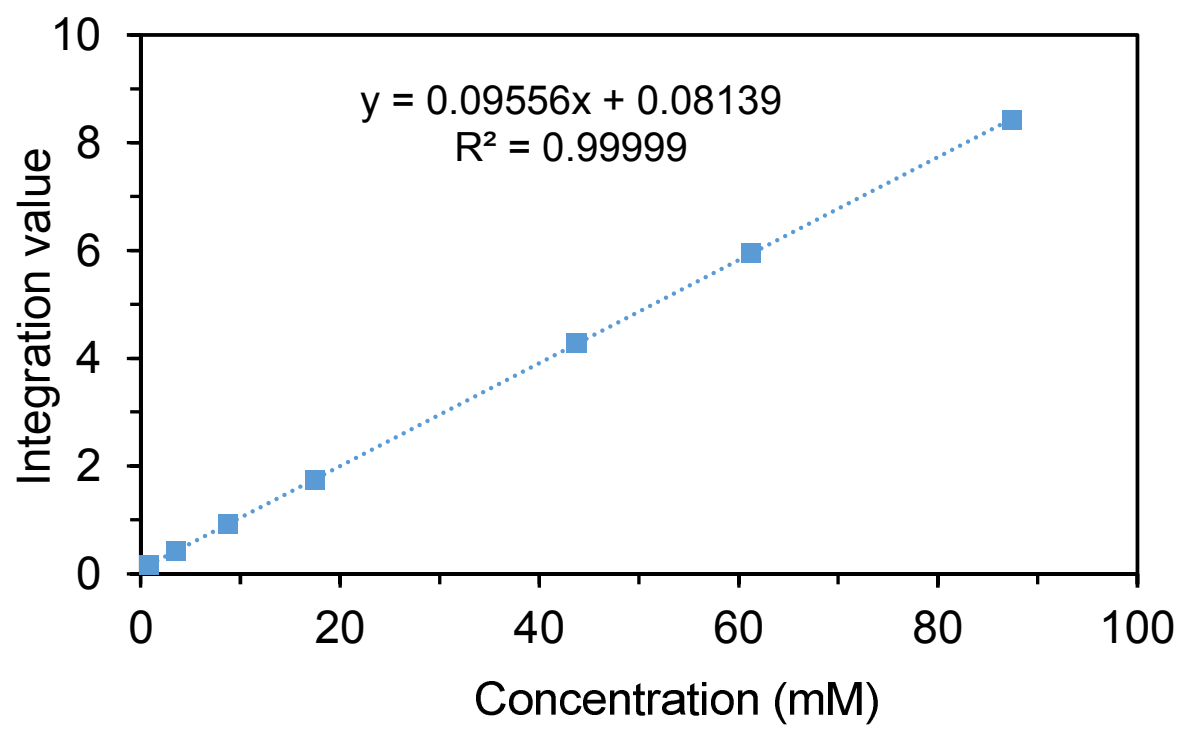

Figure S5. Calibration curve for 2-(methylthio)benzaldehyde (3) showing the linear relationship between concentration and integration of the carbonyl stretch $1620-1740 \mathrm{~cm}^{-1}$ up to $90 \mathrm{mM}$ concentration. $16 \mathrm{~s}$ data collection, $1 \mathrm{~s}$ scans repeated 16 times and summed.

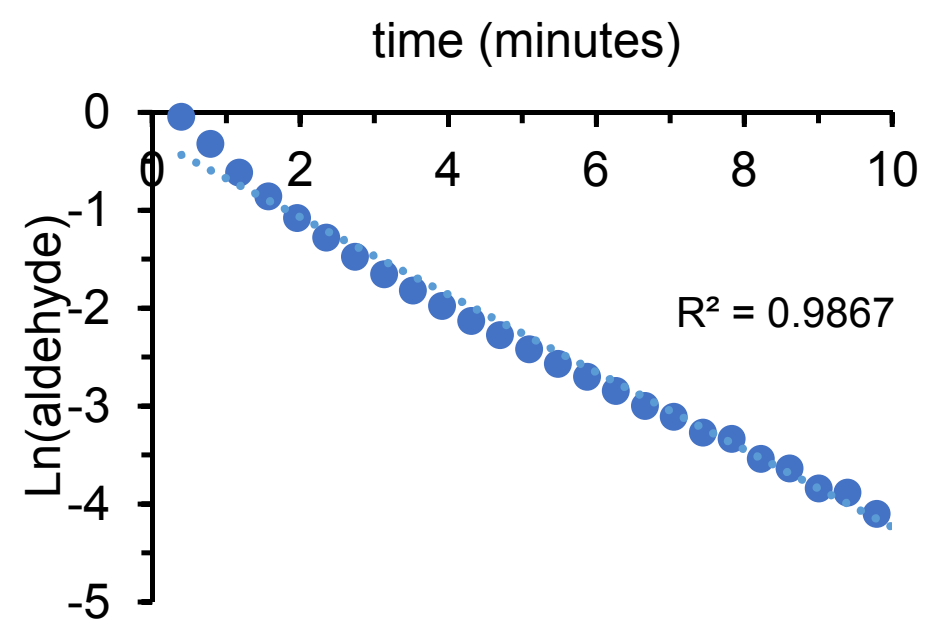

Figure S6. Plot of natural log of the signal intensity due to aldehyde against time shows a linear relationship for the reaction with $5 \%$ catalyst loading, indicating the reaction is first order overall. 


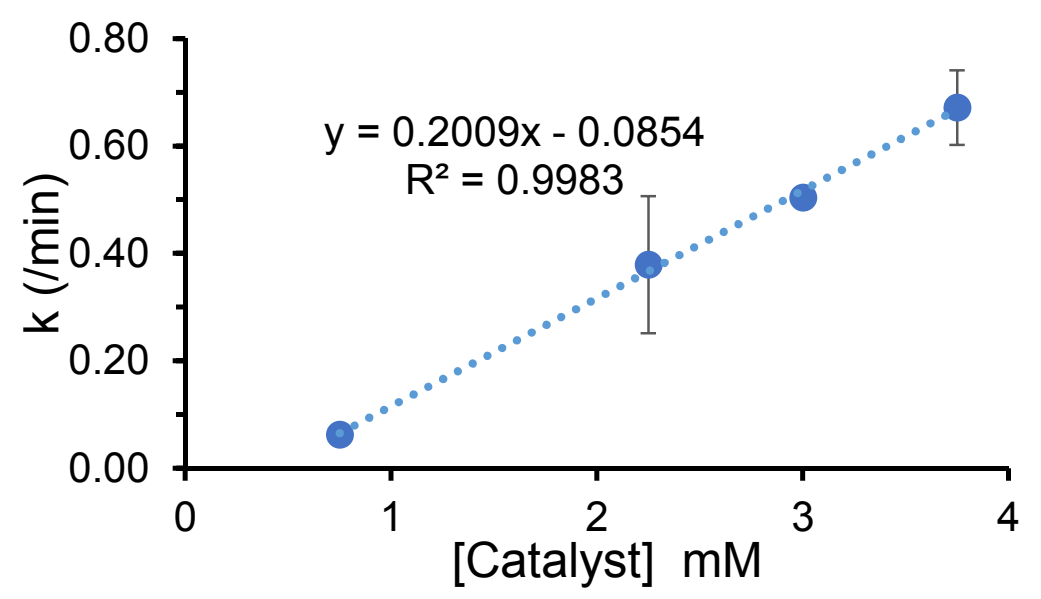

Figure S7. Catalyst concentration effect on rate constant for reaction $1-5 \%$ catalyst loadings. The line does not pass through the origin, instead it appears as if a zero rate constant would be found at about 0.4 $\mathrm{mM}$ catalyst concentration. This effect is most likely due to degradation of the catalyst by reaction with some small fixed amount of a poison in the reaction matrix. If the degradation causing reactant is at a constant amount in all these reactions, then a larger percentage of catalyst degradation would be expected at the lower catalyst loadings. This greater catalyst decomposition at low catalyst loadings is also consistent with MS results. By MS the total ion count decreases significantly over time of reaction with low catalyst loadings such as $1 \%$. This phenomenon is not observed to such an extent at higher catalyst loadings such as $5 \%$.

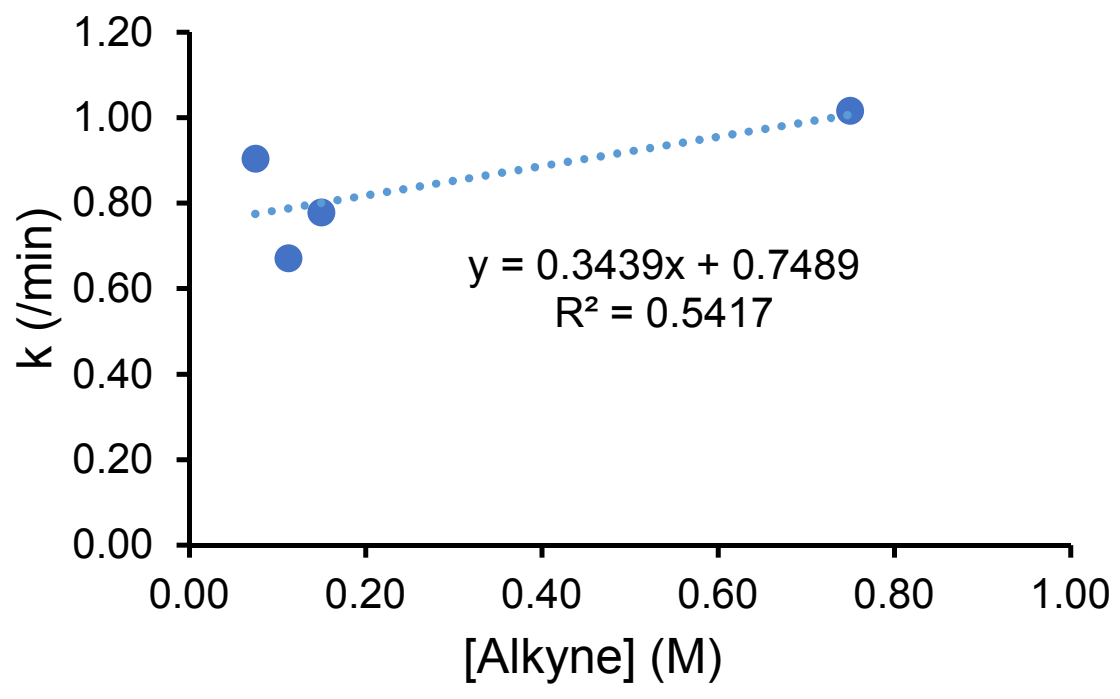

Figure S8. Alkyne loading effect on rate constant for reaction 1-10x alkyne equivalents. The possible increase in rate constant with higher alkyne equivalents could be an effect of a more disfavoured decarbonylation pathway with increasing alkyne concentration. With higher concentrations of alkyne, the coordination of the alkyne to the acyl-hydride intermediate is sped up, minimizing the time the catalyst spends as that reactive intermediate which is prone to decarbonylation. The alkyne stabilized intermediate can then undergo migration to form product instead of undergoing decarbonylation. This minimization of decarbonylations allows for more of the active catalyst to be present, thus a slight increase in the rate constants can be observed. 


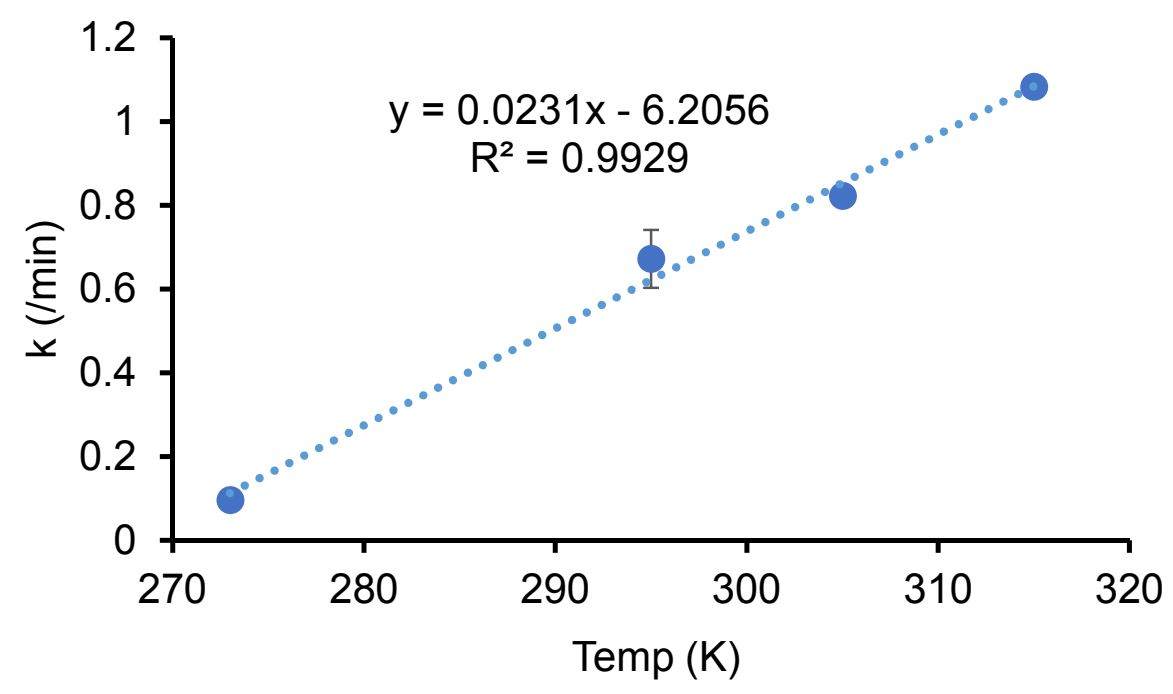

Figure S9.Temperature effect on rate constant for reaction, 273 to $315 \mathrm{~K}$.

Table S10. Summary of reaction conditions and rates.

\begin{tabular}{|c|c|c|c|c|c|c|c|}
\hline Experiment & $\begin{array}{l}\text { Temp } \\
{ }^{\circ} \mathrm{C}\end{array}$ & [Cat] & $\begin{array}{l}\text { \% Cat } \\
\text { loading }\end{array}$ & [ald] & [alkyne] & $\mathrm{k}(/ \mathrm{min})$ & $\begin{array}{l}\text { rate } \\
(\mathrm{M} / \mathrm{min})\end{array}$ \\
\hline Standard & 22 & 0.0038 & 5 & 0.075 & 0.11 & $\begin{array}{l}0.67 \pm \\
0.069\end{array}$ & $\begin{array}{r}0.050 \pm \\
0.005\end{array}$ \\
\hline temperature & 0 & 0.0038 & 5 & 0.075 & 0.11 & 0.10 & 0.007 \\
\hline temperature & 32 & 0.0038 & 5 & 0.075 & 0.11 & 0.82 & 0.062 \\
\hline temperature & 42 & 0.0038 & 5 & 0.075 & 0.11 & 1.1 & 0.081 \\
\hline cat loading & 22 & 0.0030 & 4 & 0.075 & 0.11 & 0.50 & 0.038 \\
\hline cat loading & 22 & 0.0023 & 3 & 0.075 & 0.11 & $\begin{array}{r}0.38 \pm \\
0.13\end{array}$ & $\begin{array}{r}0.028 \pm \\
0.010\end{array}$ \\
\hline cat loading & 22 & 0.0008 & 1 & 0.075 & 0.11 & $\begin{array}{r}0.06 \pm \\
0.01\end{array}$ & $\begin{array}{r}0.005 \pm \\
0.001\end{array}$ \\
\hline 1[alkyne] & 22 & 0.0038 & 5 & 0.075 & 0.08 & 0.90 & 0.068 \\
\hline 10[Alkyne] & 22 & 0.0038 & 5 & 0.075 & 0.75 & 1.0 & 0.076 \\
\hline 2[alkyne] & 22 & 0.0038 & 5 & 0.075 & 0.15 & 0.78 & 0.058 \\
\hline $\begin{array}{l}\text { 1/2[ald],1/2[ } \\
\text { cat],1/2[Alk] }\end{array}$ & 22 & 0.0019 & 5 & 0.038 & 0.06 & 0.34 & 0.013 \\
\hline 1/2[ald] & 22 & 0.0038 & 10 & 0.038 & 0.11 & 0.95 & 0.036 \\
\hline
\end{tabular}




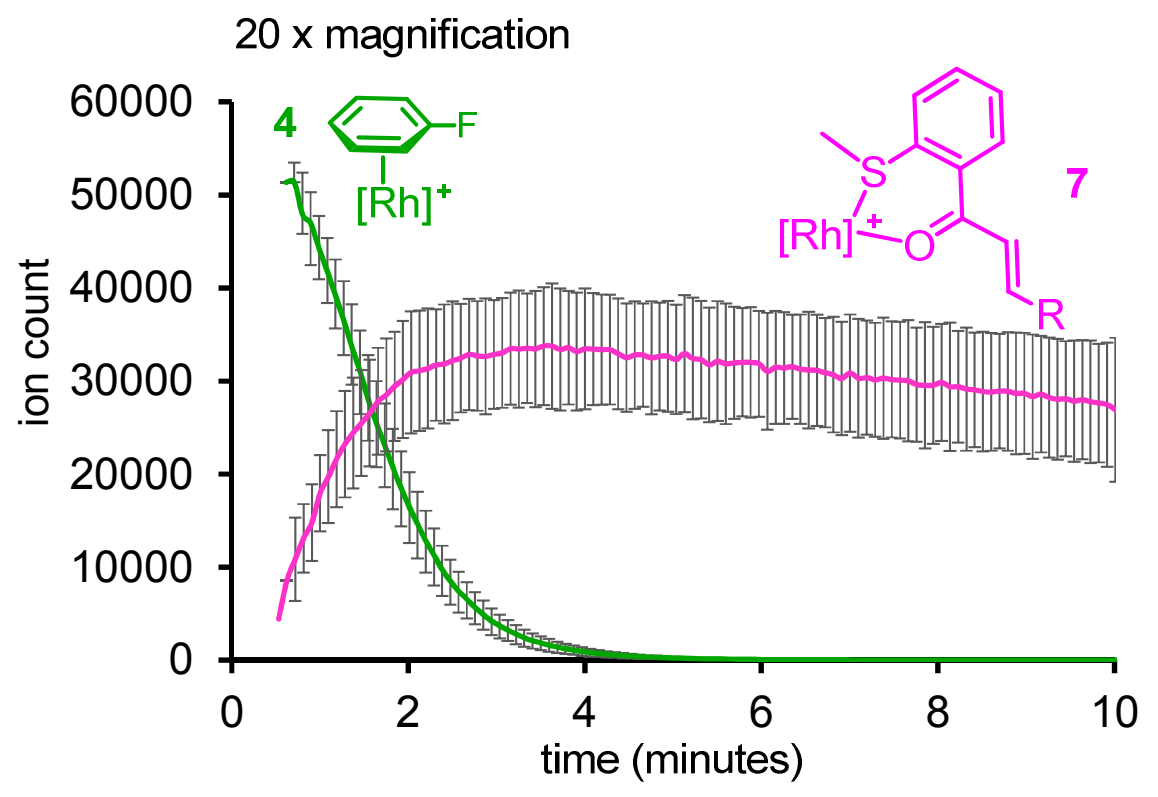

Figure S110. PSI ESI-MS reaction profile, showing only the most abundant species seen by MS (at 1/20th the concentration of aldehyde and ketone). Conditions: $75 \mathrm{mM}$ aldehyde 1, $1.13 \mathrm{mM}$ alkyne 2, 3.75 $\mathrm{mM}$ precatalyst 4. (5\% loading) in DCE as solvent, rt. Error bars are \pm one standard deviation of each data point for 7 trials.
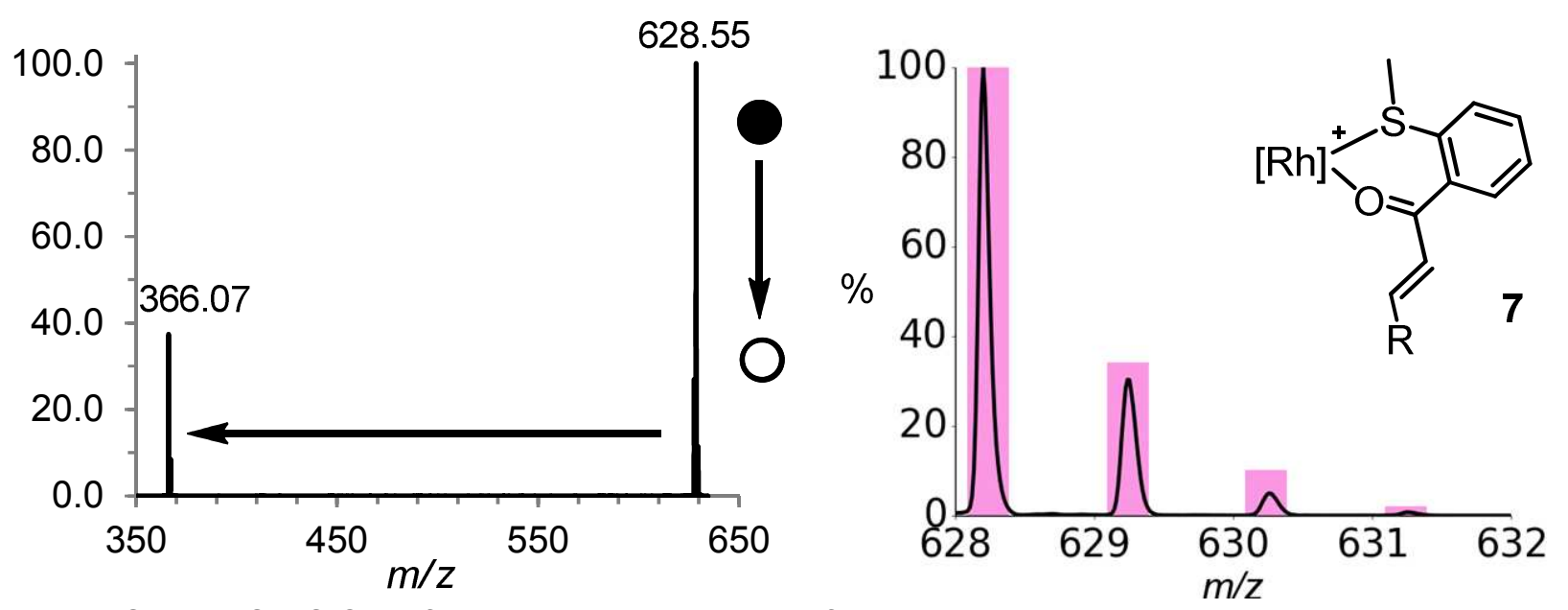

Figure S121. MS/MS CID of the cation $\mathrm{m} / \mathrm{z} 628.67$ (left) and experimental isotope pattern (black lines) superimposed with predicted isotope pattern of the predicted structure (coloured bars) with inset of proposed structure of 7 (right). The neutral loss of $262.5 \mathrm{Da}$ is that of the product ketone, to yield the catalyst $\left[R h\left(L_{2}\right)\right]^{+}$at $\mathrm{m} / \mathrm{z} 366.1$. 


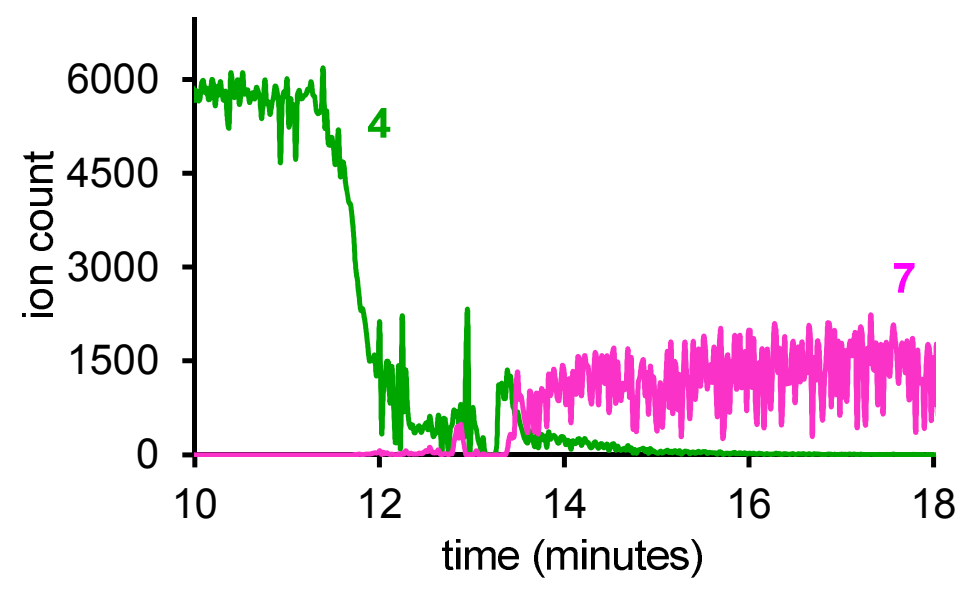

Figure S132. ESI-MS Ion count intensities of precatalyst 4 and product-bound catalyst 7 . At 11 minutes ketone 3 was added to the solution of catalyst 4 in DCE. Conditions: $3.75 \mathrm{mM}$ catalyst 4 ( $5 \%$ loading), 75 $\mathrm{mM}$ ketone 3, in DCE as solvent, RT. This shows that there is a difference in ion ion count intensity between the catalyst version $\mathbf{4}$ and $\mathbf{7}$, a higher ESI spray efficiency for $\mathbf{4}$ is most likely explanation of this.

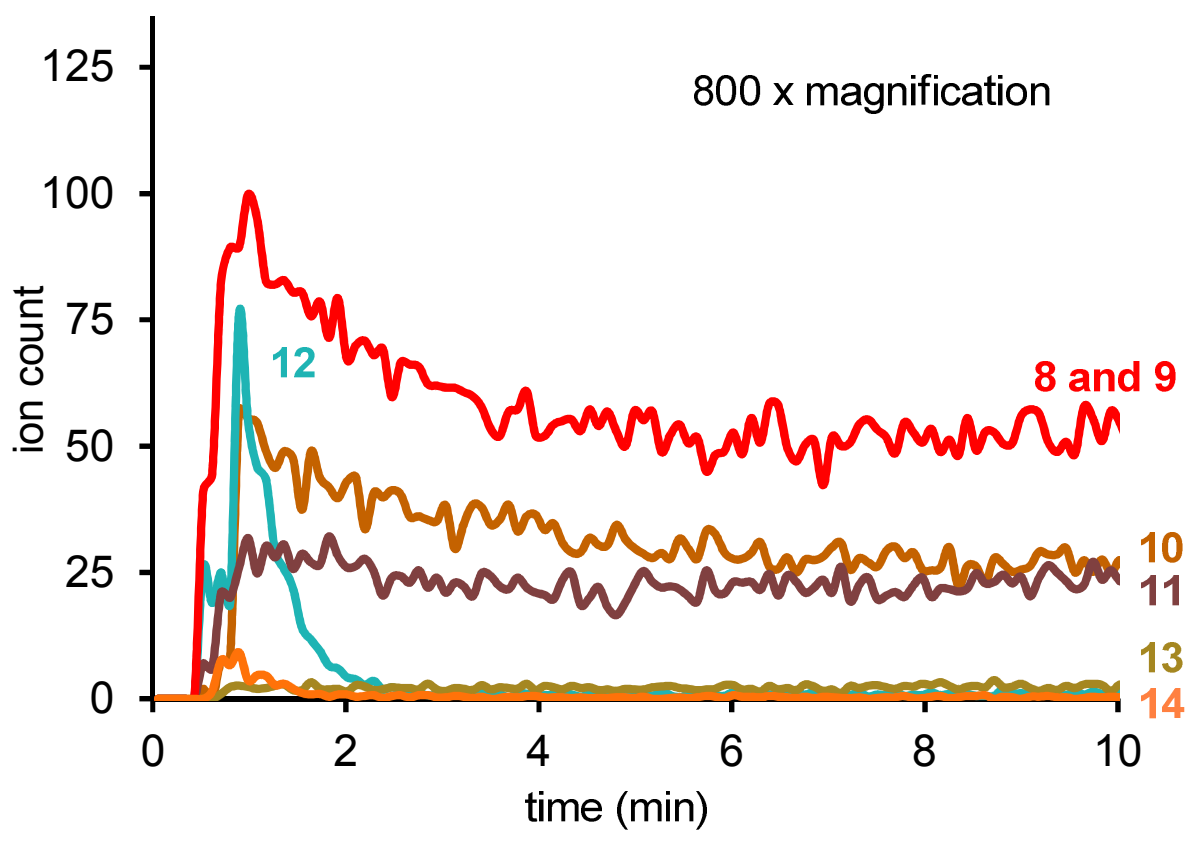

Figure S143. PSI ESI-MS reaction profile, showing species with abundances $\sim 1 / 8000^{\text {th }}$ that of the aldehyde. Conditions: $75 \mathrm{mM}$ aldehyde 1, $113 \mathrm{mM}$ alkyne 2, $3.75 \mathrm{mM}$ catalyst 4 (5\% loading) in DCE as solvent, RT. 

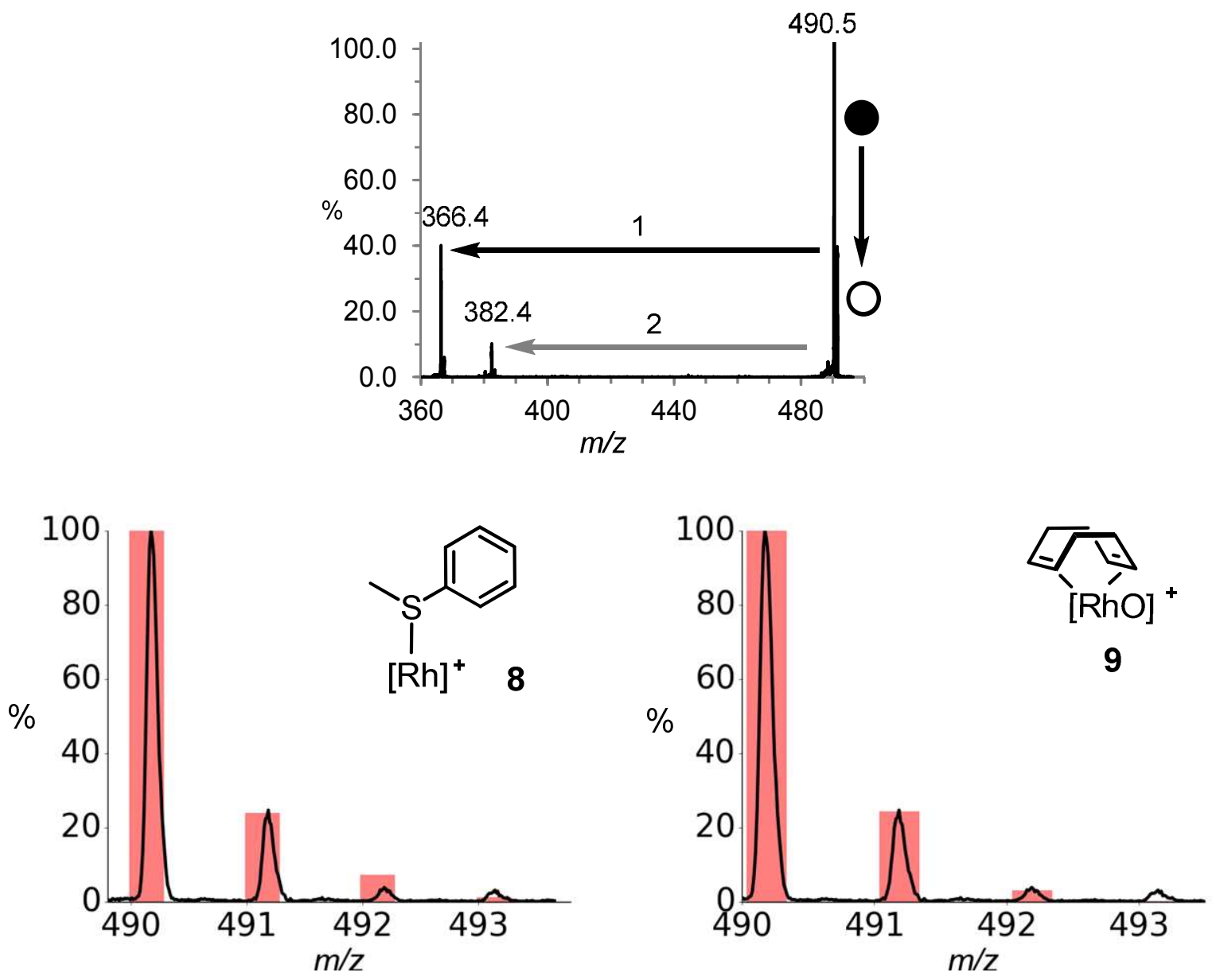

Figure S14. MS/MS CID of the cation $\mathrm{m} / \mathrm{z}$ 490.5. (top) The MS/MS has an initial neutral loss 1 of 124.14 $\mathrm{Da}(\mathrm{MeSPh})$, forming the unsaturated $\left[\mathrm{Rh}\left(\mathrm{L}_{2}\right)\right]^{+}$at $\mathrm{m} / \mathrm{z} 366.4$, which supports the structure of 8 . A different loss of $108.1 \mathrm{Da}$ is also observed, likely cyclooctadiene, to render the cation $\mathrm{m} / \mathrm{z} 382.4$ which is likely $\left[\mathrm{Rh}\left(\mathrm{L}_{2}\right) \mathrm{O}\right]^{+}$which would support the structure 9 . Therefore it is most likely that there are two overlapping species present. The experimental isotope pattern (black lines) superimposed with predicted isotope patterns with insets of proposed structures for $\mathbf{8}$ (lower left) and $\mathbf{9}$ (lower right). 

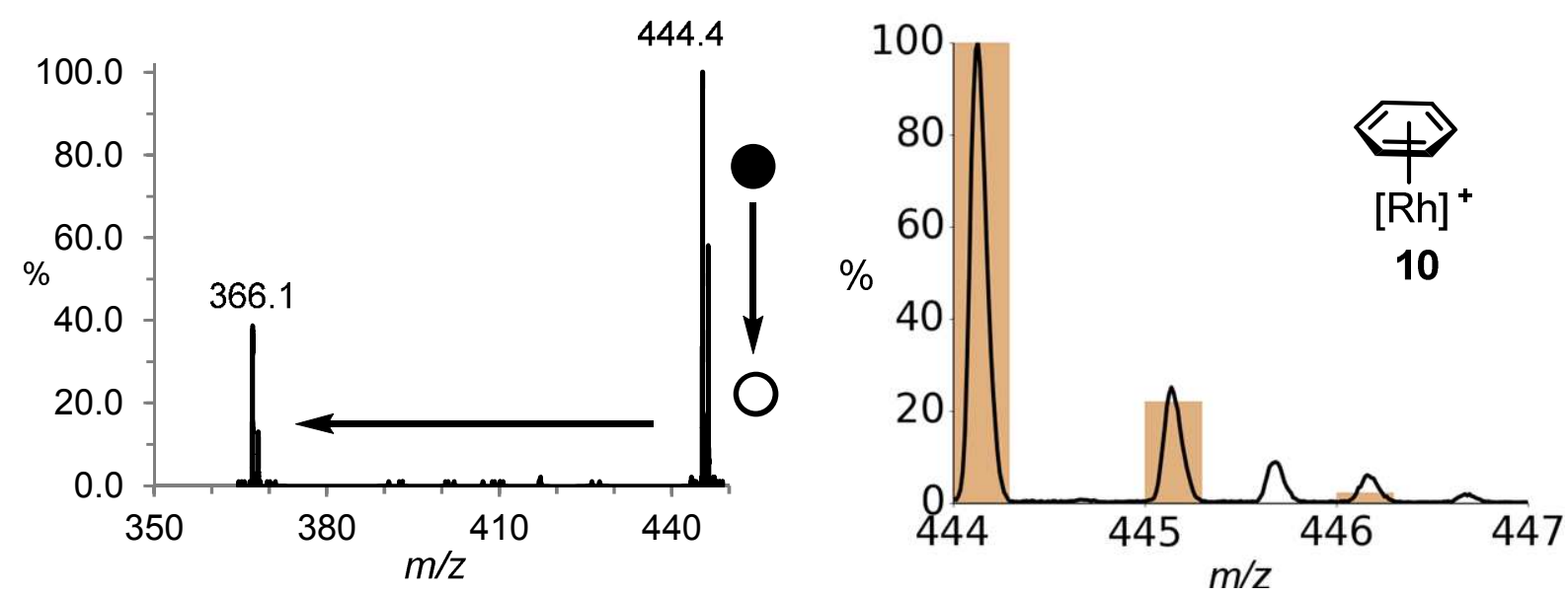

Figure S155. MS/MS CID of the cation $\mathrm{m} / \mathrm{z} 444.410$ (left) and experimental isotope pattern (black lines) superimposed with predicted isotope pattern of the predicted structure (coloured bars) with inset of proposed structure of $\mathbf{1 0}$ (right). The MS/MS of $\mathbf{1 0}$ generated a neutral loss of $78.3 \mathrm{Da}\left(\mathrm{C}_{6} \mathrm{H}_{6}\right)$ to produce the fragment $\left[R h\left(L_{2}\right)\right]^{+}$at $\mathrm{m} / \mathrm{z} 366.1$. An explanation for the presence of benzene is that the catalyst was synthesized in fluorobenzene, which inevitably contains a small amount of benzene.
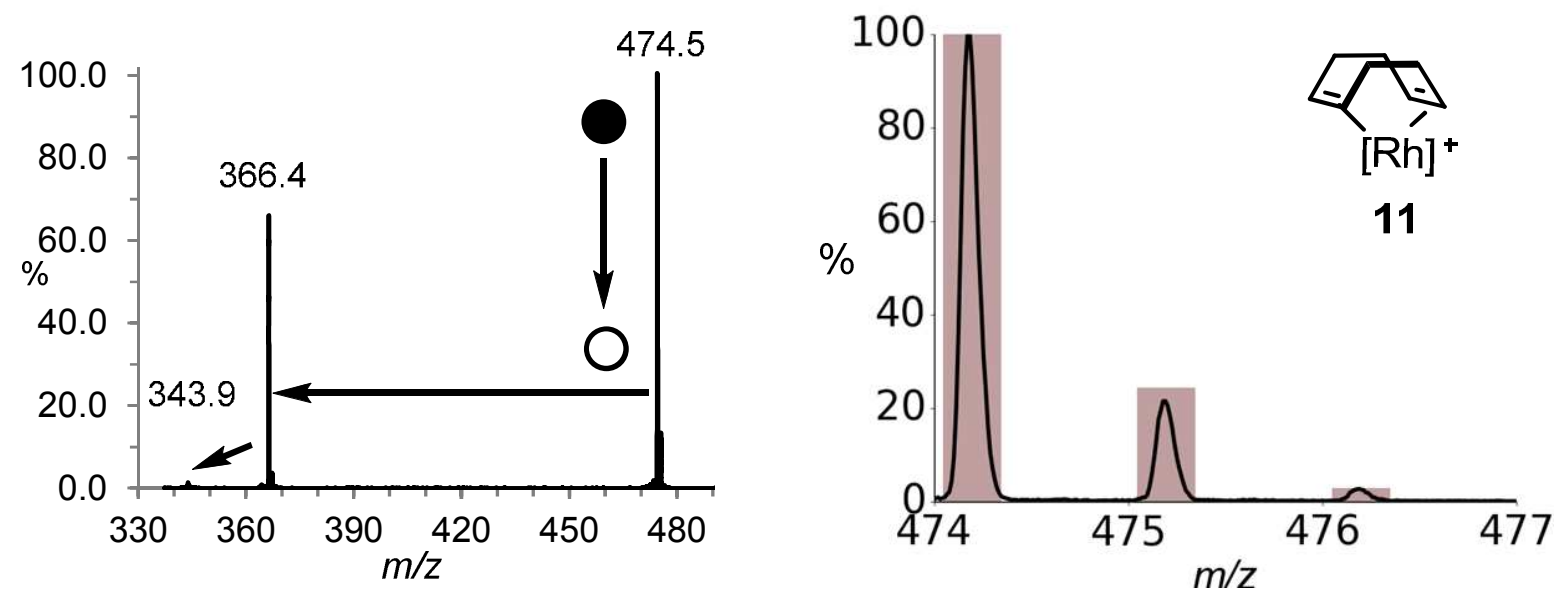

Figure S16. MS/MS CID of the cation $\mathrm{m} / \mathrm{z} 474.511$ (left) and experimental isotope pattern (black lines) superimposed with predicted isotope pattern of the predicted structure (coloured bars) with inset of proposed structure of 11 (right). MS/MS of 11. shows a neutral loss of $108.1 \mathrm{Da}$ to form $\left[R h\left(\mathrm{~L}_{2}\right)\right]^{+}$at $\mathrm{m} / \mathrm{z}$ 366.4. This mass corresponds to that of cyclooctadiene (COD). The precatalyst 4 is synthesized from

$\left[\mathrm{Rh}(\mathrm{COD})_{2}\right]^{+}$through a hydrogenation in the presence of the bisphosphine ligand and FPh. 11 is an incomplete product of the reaction for the synthesis of the starting catalyst 4 . Again, its temporal evolution is such that it is inert in the reaction would be expected as the COD ligand would bind strongly to Rh with the advantageous chelate effect. 


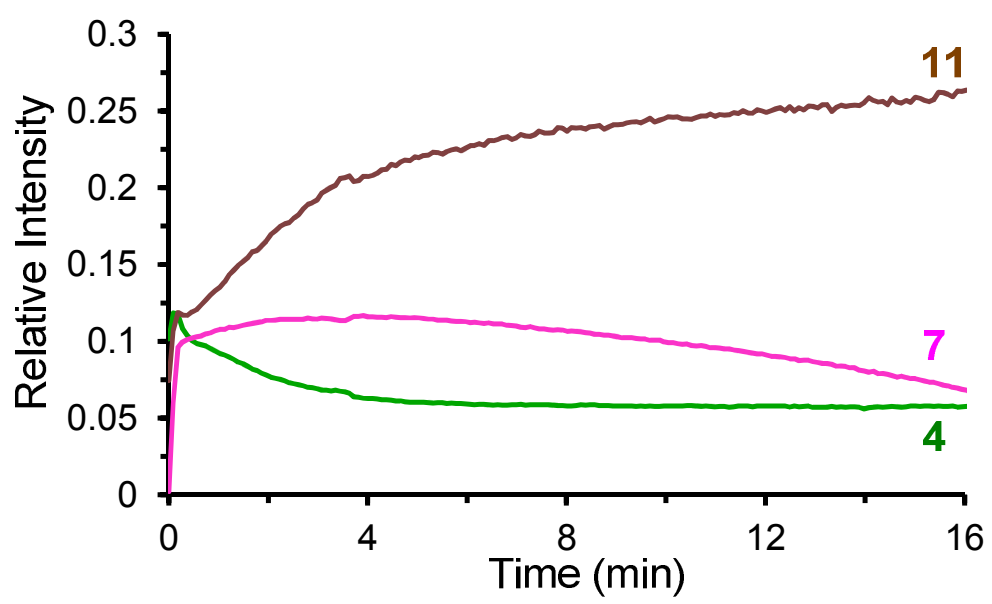

Figure S177. PSI-ESI Reaction profile where $5 \%$ loading equivalent of COD (3.75mM), aldehyde 1 $(0.075 \mathrm{M})$ and 1-octyne $2(0.1125 \mathrm{M})$ in 1,2-dichloroethane, was well stirred, to which catalyst $4(5 \%$ loading, $3.75 \mathrm{mM}$ ) was added to initialize reaction.
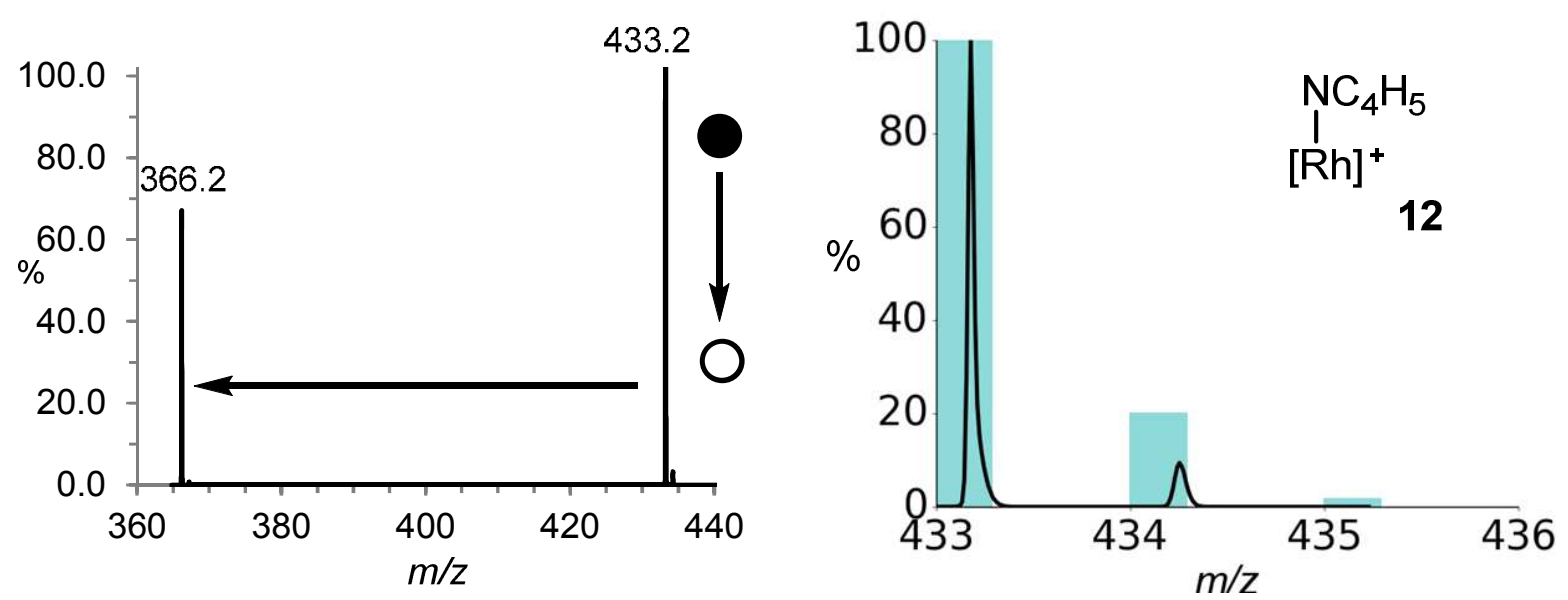

Figure S188. MS/MS CID of the cation $\mathrm{m} / \mathrm{z} 433.212$ (left) and experimental isotope pattern (black lines) superimposed with predicted isotope pattern of the predicted structure (coloured bars) with an inset of proposed structure of 12 (right). MS/MS information shows it is made up of $\left[R h\left(L_{2}\right)\right]^{+}$and a neutral mass of $67 \mathrm{Da}$. The most accurate mass prediction for the neutral mass lost is the formula $\mathrm{C}_{4} \mathrm{H}_{5} \mathrm{~N}$. Pyrrole is used as a stabilising agent in some chlorinated solvents, acting to slow oxidation and condensation reaction. The pyrrole could be acting as an L-type ligand with the nitrogen as a 2 electron donor, to then be displaced by the aldehyde 1 in the hydroacylation reaction, 12 thus acting as a precatalyst. 

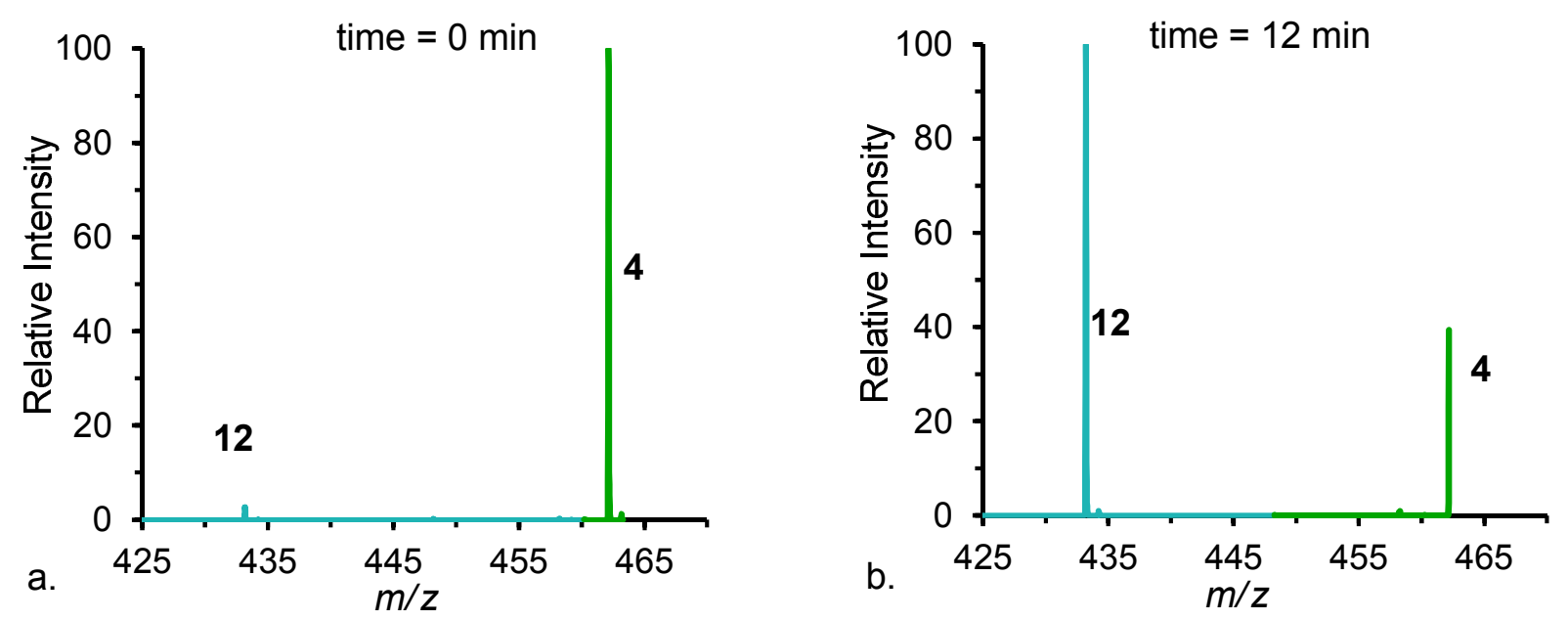

Figure S19. (a) ESI-MS of A before addition of pyrrole; (b) 12 minutes after addition of pyrrole to a solution of $\mathbf{A}$. in DCE. $\left[\mathrm{Rh}\left(\mathrm{L}_{2}\right)(\text { pyrrole })\right]^{+}$forms and has an MS/MS product spectrum identical to that of species I.
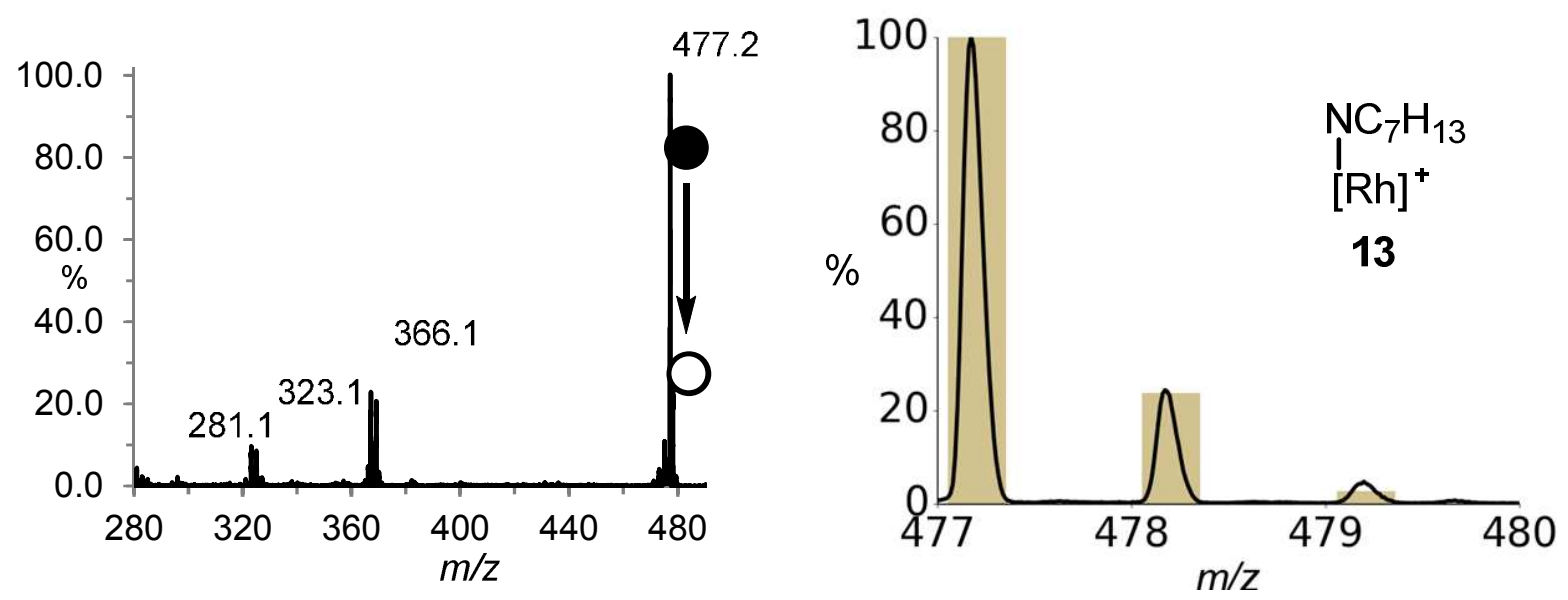

Figure S190. MS/MS CID of the cation $\mathrm{m} / \mathrm{z} 477.213$ (left) and experimental isotope pattern (black lines) superimposed with predicted isotope pattern of the predicted structure (coloured bars). Inset of proposed structure of 13 (right). The most likely chemical formula for a monoisotopic mass of $111.1 \mathrm{Da}$ is $\mathrm{C}_{7} \mathrm{H}_{13} \mathrm{~N}$. 

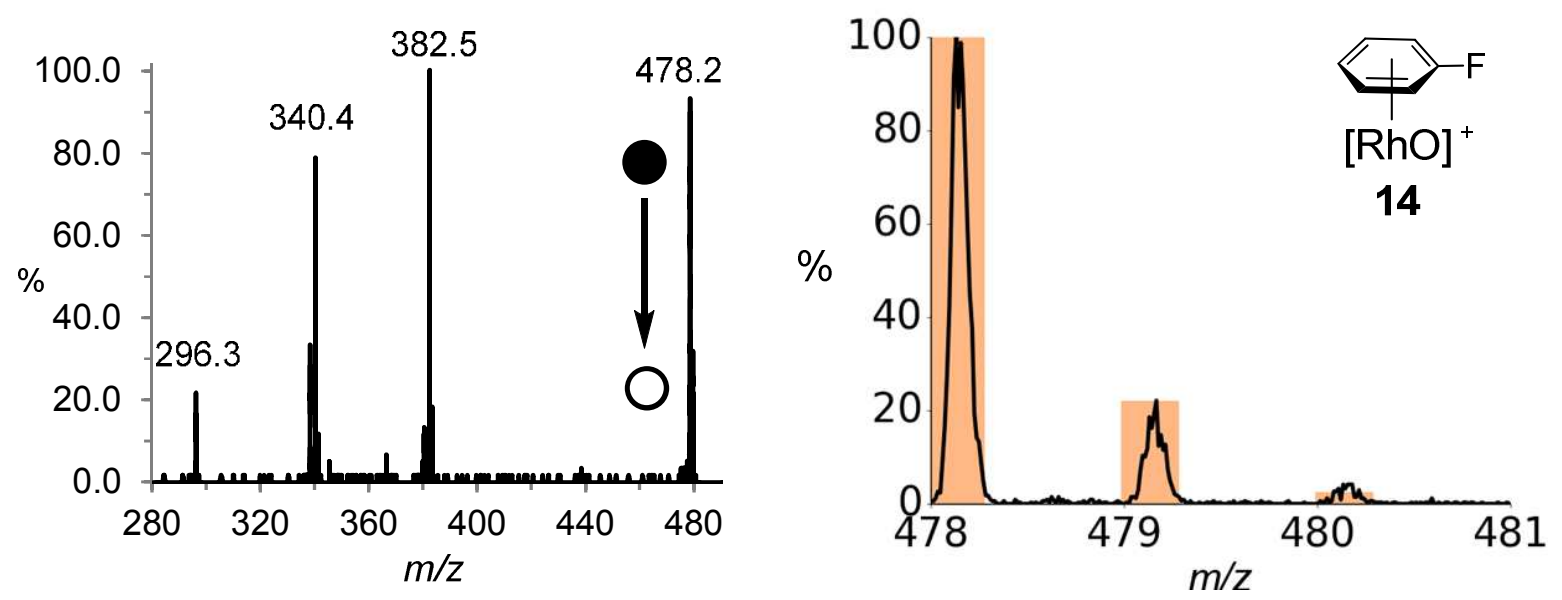

Figure S201. MS/MS CID of the cation $\mathrm{m} / \mathrm{z} 478.214$ (left) and experimental isotope pattern (black lines) superimposed with predicted isotope pattern of the predicted structure (coloured bars). Inset of proposed structure of 14 (right). Loss of PhF generates an ion at $m / z$ 382, 16 greater than $\left[R h\left(L_{2}\right)\right]^{+}$. 

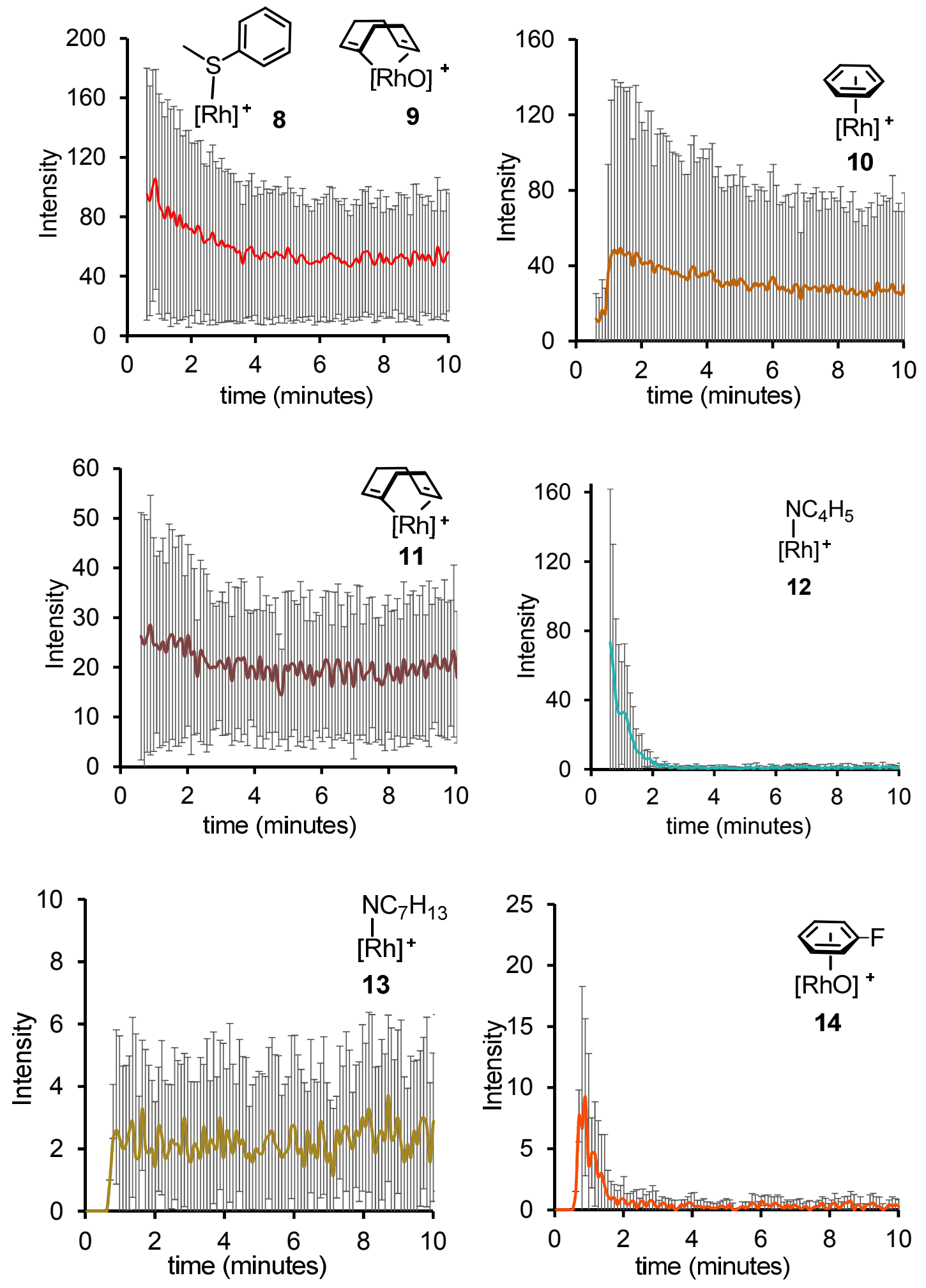

Figure S212. Reproducibility of the PSI ESI-MS reaction traces for 8-14. Error bars are \pm one standard deviation of each data point for 7 trials. The trials were conducted over an extended period (months) and involved different batches of solvent. 


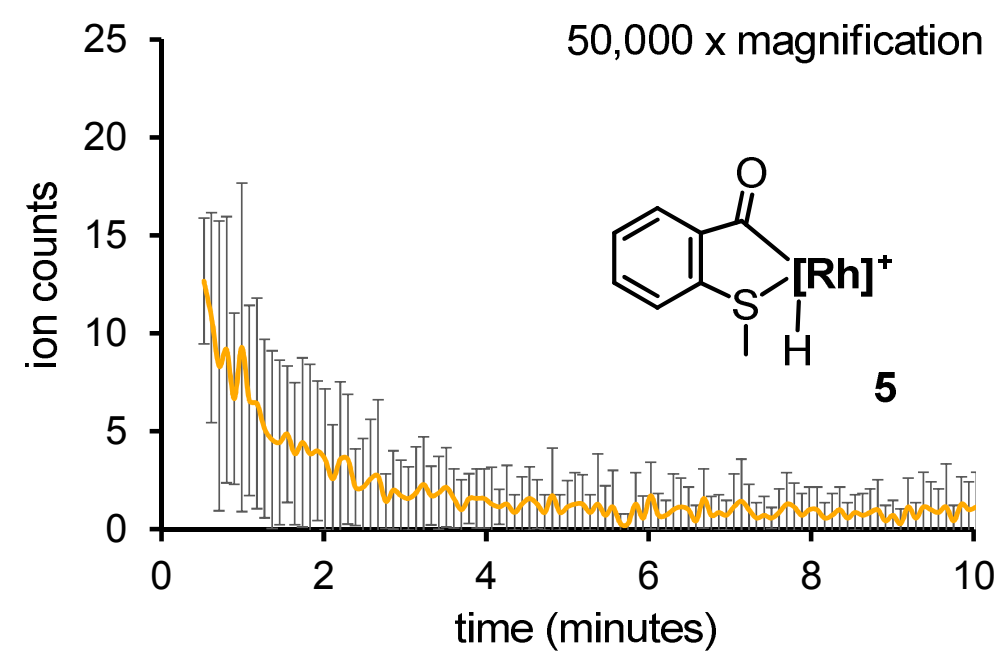

Figure S223. PSI ESI-MS reaction profile for 5 error bars are \pm one standard deviation of each data point for 7 trials. Conditions: $75 \mathrm{mM}$ aldehyde $1,1.13 \mathrm{mM}$ alkyne $2,3.75 \mathrm{mM}$ catalyst $\mathbf{A}$. (5\% loading) in

1,2-dichloroethane as solvent, rt. The dynamics of $\mathbf{5}$ indicates that it is a likely intermediate as its abundance closely matches the overall rate of reaction.
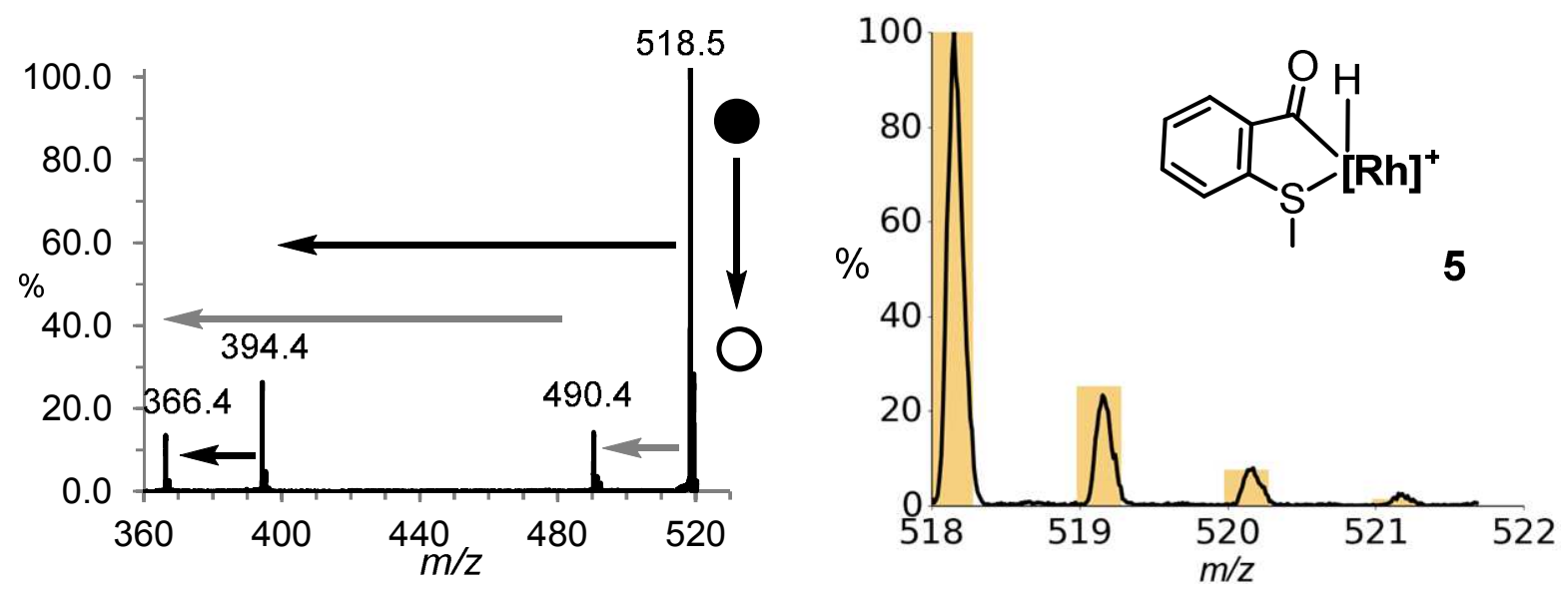

Figure S234. MS/MS CID of the cation 5 at $\mathrm{m} / \mathrm{z} 518.5$ (left) and experimental isotope pattern (black lines) superimposed with predicted isotope pattern of the predicted structure (coloured bars) with inset of proposed structure of $\mathbf{5}$ (right). MS/MS of $\mathbf{5}$. shows the neutral loss of $124.1 \mathrm{Da}$ followed by $28.0 \mathrm{Da}$ as is shown by black arrows, to form the fragment $\left[R h\left(L_{2}\right)\right]^{+}$at $\mathrm{m} / \mathrm{z} 366.4$. The grey arrows show the loss of $28.0 \mathrm{Da}$, followed by the loss of 124.1 also resulting in the fragment $\left[R h\left(L_{2}\right)\right]^{+}$at $\mathrm{m} / z 366.4$. The loss of 28 corresponds to the loss of a CO, while the loss of 124.1 corresponds to the loss of MeSPh. The CID process is causing the reductive decarbonylation for the elimination of MeSPh and CO separately. If 5 were simply a combination of the aldehyde (1) and $[\mathrm{Rh}]^{+}$(i.e. no oxidative addition) we would expect to see simple loss of the aldehyde only. 


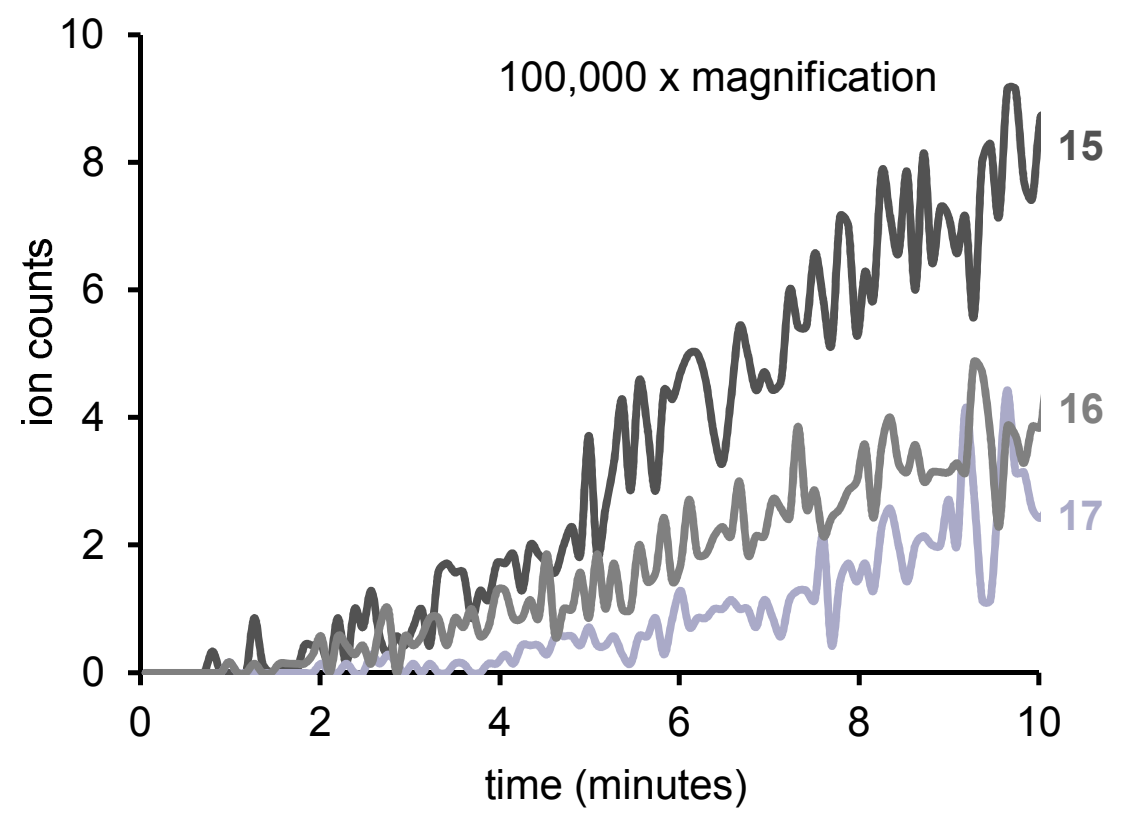

Figure S245. PSI ESI-MS reaction profile, decomposition product, ultra-low abundance species.

Conditions: $75 \mathrm{mM}$ aldehyde 1, $113 \mathrm{mM}$ alkyne 2, $3.75 \mathrm{mM}$ catalyst 4. (5\% loading) in DCE as solvent, rt. All of these species grew in over time, a trend that would be predicted of decomposition products.

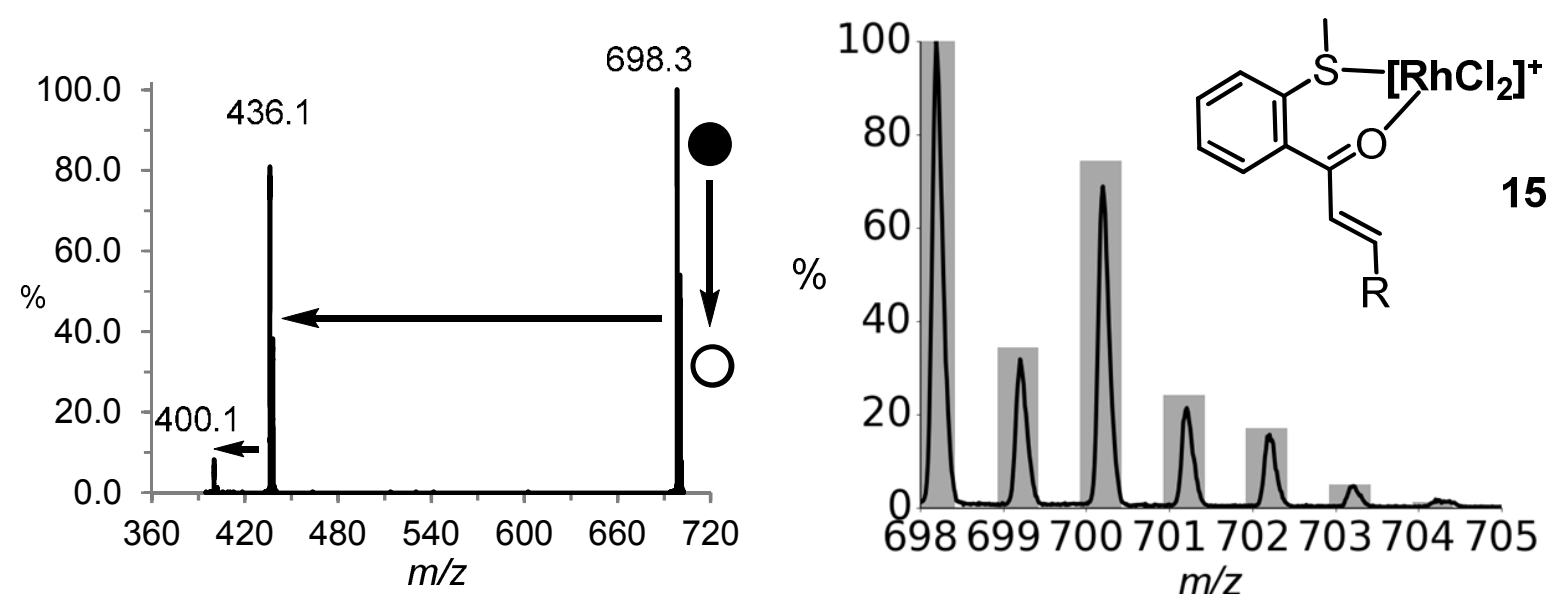

Figure S256. MS/MS CID of the cation $\mathrm{m} / \mathrm{z} 698.315$ (left) and experimental isotope pattern (black lines) superimposed with predicted isotope pattern of the predicted structure (grey bars) with inset of proposed structure of 15 (right). The initial loss of $262.2 \mathrm{Da}$ is due to the loss of the ketone product, this is followed by a loss of $36(\mathrm{HCl})$, to form an ion with $\mathrm{m} / \mathrm{z} 400.1$. 


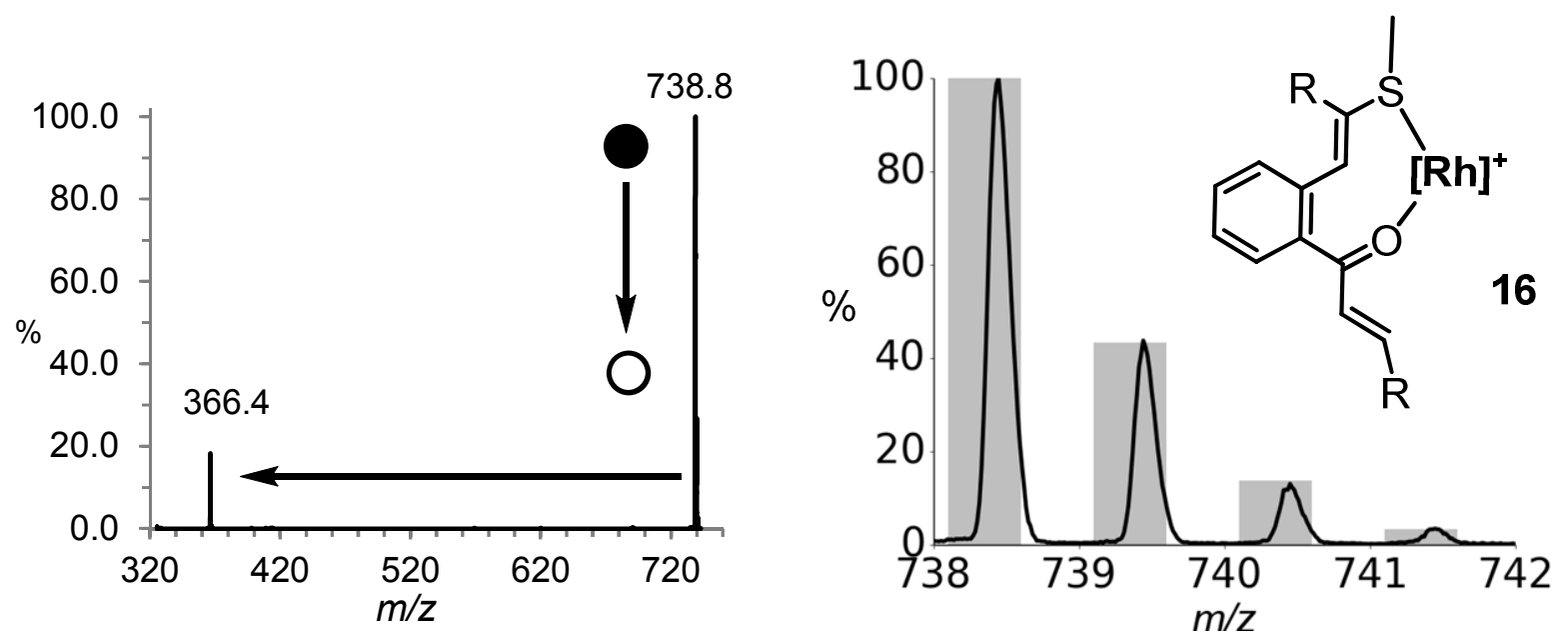

Figure S267. MS/MS CID of the cation $\mathrm{m} / \mathrm{z} 738.816$ (left) and experimental isotope pattern (black lines) superimposed with predicted isotope pattern of the predicted structure (grey bars) with inset of proposed structure of 16 (right). 16 dissociates to $366.0 \mathrm{~m} / \mathrm{z}\left[\left(\mathrm{Rh}\left(\mathrm{L}_{2}\right)\right]^{+}\right.$by neutral loss of $372.4 \mathrm{Da}$ which is the mass of one aldehyde and two of the alkynes employed. As an excess of alkyne was used during these reactions, it is reasonable that this species may form.
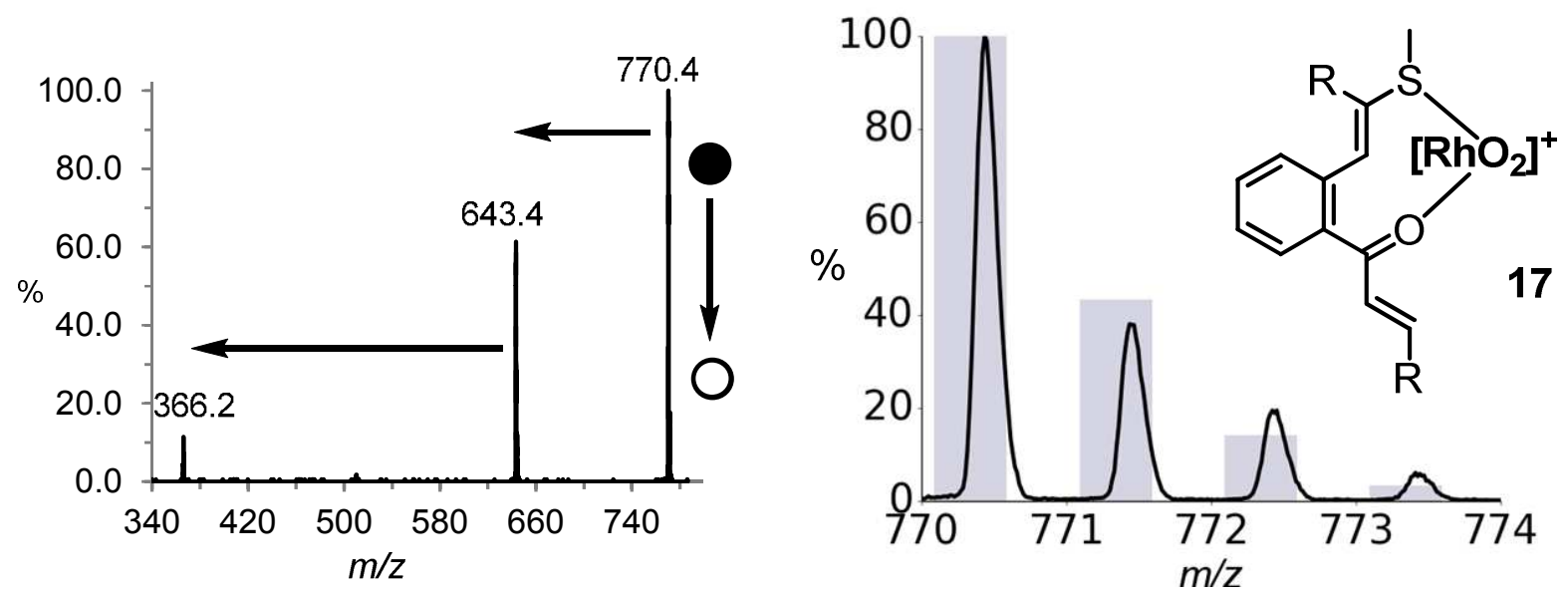

Figure S278. MS/MS CID of the cation $\mathrm{m} / \mathrm{z} 770.417$ (left) and experimental isotope pattern (black lines) superimposed with predicted isotope pattern of the predicted structure (grey bars) with inset of proposed structure of 17 (right). The location of the two oxygens on 17 is unknown. The MS/MS data shows fragmentation via loss of 126 (alkyne +0 ) followed by 278 (product $+O$ ), suggesting the two $O$ are not

involved directly with $\mathrm{Rh}$ or with the bisphosphine ligand. Further speculation given the very low concentrations observed is unwarranted. 

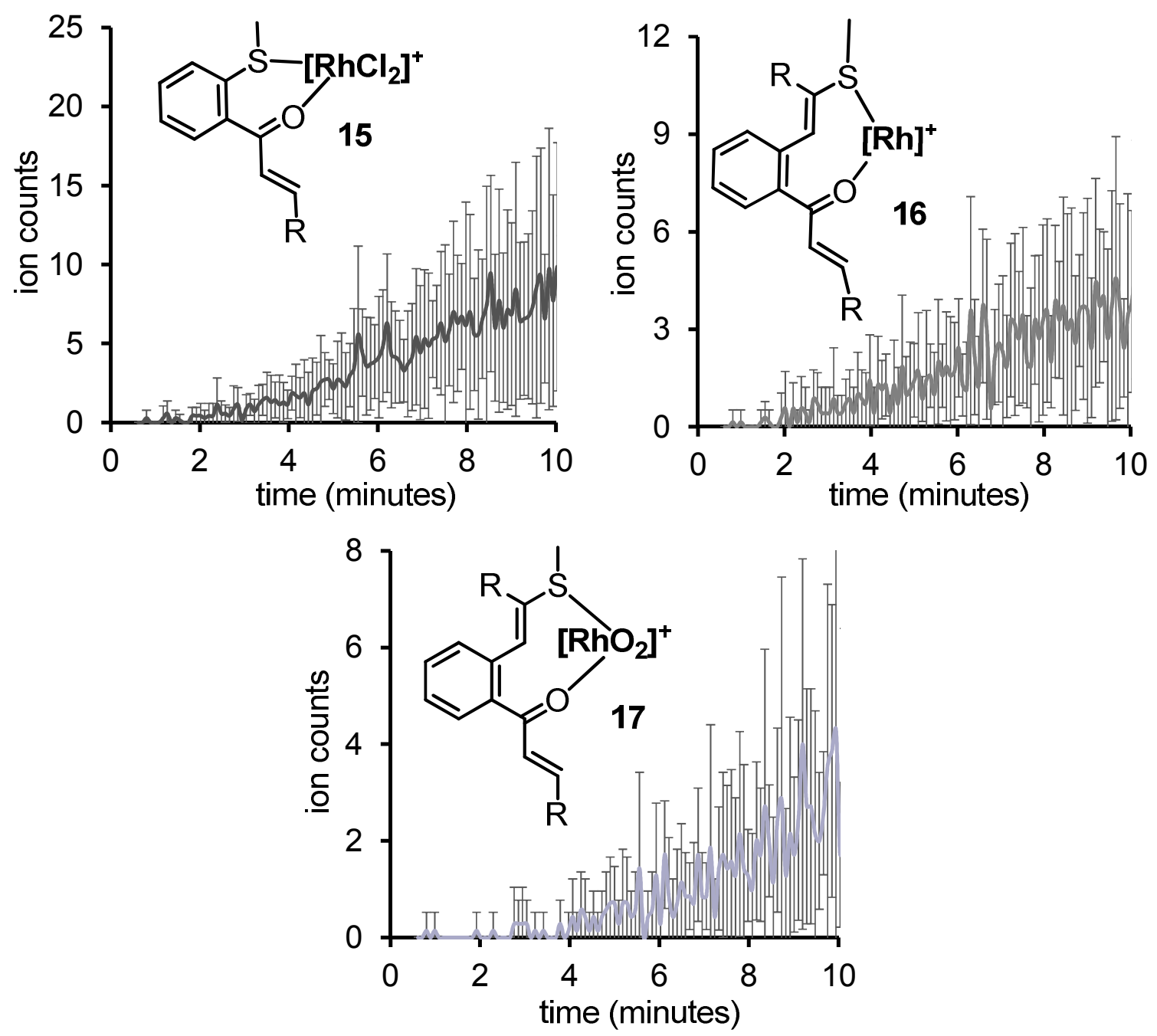

Figure S29. PSI ESI-MS reaction traces of 15,16 , and 17. error bars are \pm one standard deviation of each data point for 7 trials.

\section{Reference}

1. Silverstein, R. M.; Webster, F. X.; Kiemle, D. Spectrometric Identification of Organic

Compounds. (Wiley, Hoboken, 2005). 